\title{
Sonication Enhanced Removal of Nickel and Cobalt Ions from Polluted Water Using an Iron Based Sorbent
}

\author{
Zari Hooshyar, ${ }^{1,2}$ Ghasem Rezanejade Bardajee, ${ }^{2}$ and Yousef Ghayeb ${ }^{1}$ \\ ${ }^{1}$ Department of Chemistry, Isfahan University of Technology, Isfahan, Iran \\ ${ }^{2}$ Department of Chemistry, Payame Noor University, P.O. Box 19395-3697, Tehran, Iran \\ Correspondence should be addressed to Ghasem Rezanejade Bardajee; rezanejad@pnu.ac.ir
}

Received 16 June 2012; Revised 26 August 2012; Accepted 8 September 2012

Academic Editor: Qing Li

Copyright (c) 2013 Zari Hooshyar et al. This is an open access article distributed under the Creative Commons Attribution License, which permits unrestricted use, distribution, and reproduction in any medium, provided the original work is properly cited.

\begin{abstract}
The effect of sonication time on removal efficiency of $\mathrm{Ni}^{2+}$ and $\mathrm{Co}^{2+}$ from wastewater in the presence of zero valence iron (ZVI) nanoparticles is described. The results showed that the presence of cobalt ions in the solution enhances the removal efficiency of nickel by ZVI nanoparticles to about $64 \%$ which is one of the advantages of this protocol.
\end{abstract}

\section{Introduction}

Zero valence materials are important for the PRB (permeable reactive barrier) facilities. Over the past decades, $\mathrm{PRBs}$ have been developed and used to treat contaminated ground water by different contaminants [1-8]. In these barriers, zero valence iron (ZVI) can be used as a reactive material to reduce and stabilize different types of ions. Compared to powder or granular ZVI, nanoscale ZVI can largely increase the uptake capacity due to the high surface to volume ratio [9]. This reactivity can be improved about 30 times relative to iron powders [10]. High surface reactivity of ZVI nanoparticles have been used for in situ remediation of several kinds of contaminants. Most investigations have been originally focused on the remediation of chlorinated hydrocarbons such as tetrachloroethene (PCE), trichloroethene (TCE), carbon tetrachloride (CT), organochlorine pesticides (like DDT and lindane), and nitro aromatic compounds in aqueous streams [11-20]. Recent investigations have shown that heavy metals including arsenic, lead, chromium, cadmium, uranium, molybdenum, and mercury also can be reduced by ZVI nanoparticles as well [21-29]. ZVI nanoparticles remove chlorinated contaminants of aqueous media by reductive dechlorination and eliminate aqueous metal ions by their reduction to an insoluble form. A layer of ferrous hydroxide is formed in aqueous solution and hydrogen gas is liberated. As a result, ZVI particles typically have a core-shell structure with the core being zero valence iron $\left(\mathrm{Fe}^{0}\right)$ and the shell being iron oxides/hydroxides due to the iron oxidation. This structure presents the ZVI nanoparticles with high surface and unique redox potential properties for removal and transformation of contaminants [25, 27, 28]. The removal efficiency is related to the surface area or the size of used ZVI nanoparticles, the $\mathrm{pH}$, and composition of the solution. Acoustic cavitations can increase the surface area of the reactive solids by rupture of the particles. Sonication in the presence of $\mathrm{Fe}^{0}$ has been explored for the dechlorination of carbon tetrachloride. Results showed that the coupled ultrasound and iron systems compare to the degradation by direct reaction with $\mathrm{Fe}^{0}$ enhanced the overall degradation rate about $40 \%$. The enhancement was attributed to the continuous cleaning and chemical activation of the $\mathrm{Fe}^{0}$ surfaces by the combined chemical and physical effects of acoustic cavitations, to shatter the particles, and accelerate mass transport of reacting substances to the $\mathrm{Fe}^{0}$ surfaces [28].

Herein, we describe the treatment of common ground water heavy metals pollutants such as $\mathrm{Ni}^{2+}$ and $\mathrm{Co}^{2+}$ by ZVI nanoparticles in separate as well as mixture batch experiments, respectively. Nickel and cobalt were selected as target substances, because they have been listed in the priority pollutants by the United States Environmental Protection Agency as a persistent inorganic pollutant. While the removal of $\mathrm{Ni}$ (II) from wastewater by ZVI nanoparticles has been 
TABLE 1: Standard reduction potentials at $25^{\circ} \mathrm{C}$ [31].

\begin{tabular}{lll}
\hline Element & Half-cell reaction & $E^{0}(\mathrm{~V})$ \\
\hline Iron $(\mathrm{Fe})$ & $\mathrm{Fe}^{2+}+2 \mathrm{e}^{-} \rightarrow \mathrm{Fe}$ & -0.44 \\
Nickel $(\mathrm{Ni})$ & $\mathrm{Ni}^{2+}+2 \mathrm{e}^{-} \rightarrow \mathrm{Ni}$ & -0.23 \\
Cobalt $(\mathrm{Co})$ & $\mathrm{Co}^{2+}+2 \mathrm{e}^{-} \rightarrow \mathrm{Co}$ & -0.28 \\
\hline
\end{tabular}

widely investigated, very little works have been performed on the removal of $\mathrm{Co}(\mathrm{II}), \mathrm{Ni}(\mathrm{II})$, and their mixtures from wastewater. In addition, there is no report on the application of sonication in these systems. In this regard, particular attention is devoted to the effect of sonication on the removal of nickel and cobalt pollutants by ZVI nanoparticles near neutral $\mathrm{pH}$ value.

\section{Experiments}

2.1. Materials and Instruments. All chemicals, including nickel nitrate $\left(\mathrm{Ni}\left(\mathrm{NO}_{3}\right)_{2} \cdot 6 \mathrm{H}_{2} \mathrm{O}, 99 \%\right.$, Merck), cobalt nitrate $\left(\mathrm{Co}\left(\mathrm{NO}_{3}\right)_{2} \cdot 6 \mathrm{H}_{2} \mathrm{O}, 99 \%\right.$, Merck), and iron nanoparticles $\left(\mathrm{Fe}^{0}, 97 \%, 12 \mathrm{~nm}\right.$ diameter, spherical, Research Institute of Petroleum Industry, Iran), were used as received. Sonications were performed in a Sonopuls-HD3200 (Bandelin, Germany) consisting of microtip MS 73, $3 \mathrm{~mm}$ diameter at $70 \%$ amplitude with a frequency of $20 \mathrm{kHz}$ and a nominal power $200 \mathrm{~W}$.

2.2. Experiment Procedure. Solutions of nickel and cobalt with the same initial concentrations $(50 \mathrm{mg} / \mathrm{L})$ were prepared separately in glass reactor and ZVI nanoparticles (0.03 gr) were added to each one at ambient temperature $\left(22-25^{\circ} \mathrm{C}\right)$. The nanoparticles were dispersed by sonications from 0 to 40 minutes with 5 minutes intervals to obtain the optimum sonication time for the highest removal efficiency (Figure 1). Then, the absorbed metals on the surface of ZVI nanoparticles were separated by magnetic field ( 0.5 Tesla) and lastly the suspension was centrifuged for one hour at $3600 \mathrm{rpm}$. The concentration of the residual metal ions in the solution was measured with an atomic absorption (AA) spectrometer (Perkin-Elmer AA 2380) using standard absorption conditions (Figure 1).

To investigate the effect of $\mathrm{Co}^{2+}$ on the removal of $\mathrm{Ni}^{+2}$ and to determine the optimum sonication time, six solutions containing, the same concentration of $\mathrm{Ni}^{+2}(50 \mathrm{mg} / \mathrm{L})$ and various concentrations of $\mathrm{Co}^{+2}(5,15,25,35,50$, and $75 \mathrm{mg} / \mathrm{L}$ ) were prepared (Figure 2).

\section{Results and Discussion}

Figures 1 and 2 show the effect of sonication times on the removal efficiency of $\mathrm{Ni}^{2+}$ and $\mathrm{CO}^{2+}$ in solutions with concentration of $50 \mathrm{mg} / \mathrm{L}$ by ZVI nanoparticles, respectively. As one can see, the maximum removal efficiency of $\mathrm{Ni}^{2+}$ is about $38 \%$ at 20 minutes of sonication while this value for $\mathrm{Co}^{+2}$ is about $59 \%$ at 30 minutes. With increasing the sonication time, the nanoclusters break down and subsequently their size decreases to reach a minimum value (optimum

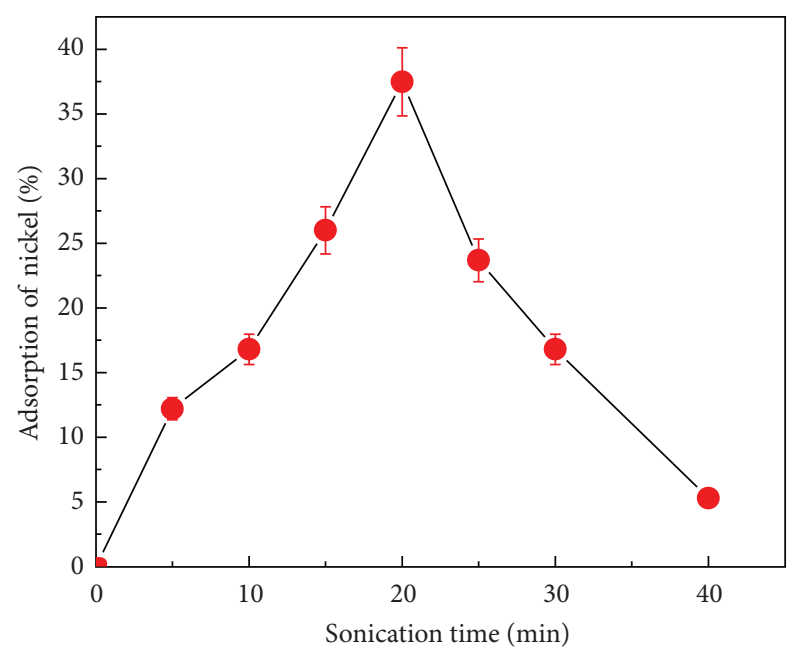

Figure 1: The effect of sonication times on the removal of $\mathrm{Ni}^{2+}$ $(50 \mathrm{mg} / \mathrm{L})$ in the presence of ZVI nanoparticles $(0.03 \mathrm{gr} / \mathrm{L})$.

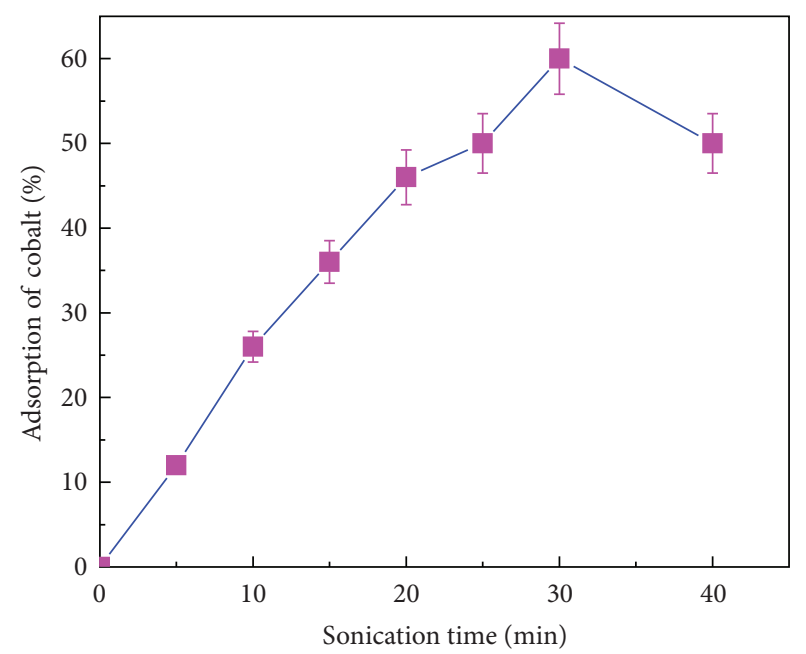

Figure 2: The effect of sonication times on the removal of $\mathrm{Co}^{2+}$ $(50 \mathrm{mg} / \mathrm{L})$ in the presence of ZVI nanoparticles $(0.03 \mathrm{gr} / \mathrm{L})$.

time). At higher sonication times, the size of nanoparticles increases again due to the aggregation of nanoparticles. This behavior was previously reported by Kwak and Kim [31] for nanoclusters of $\mathrm{CuO}$ at different sonication times. In other words, the ratio of surface to volume of the nanoclusters enhances as the ZVI nanoclusters break down.

Another feature in Figures 1 and 2 is the difference between the maximum removal efficiencies of $\mathrm{Co}^{2+}(59 \%)$ and $\mathrm{Ni}^{2+}(38 \%)$. This discrepancy may be attributed to three parameters that effect on the removal efficiency of metal ions. First, according to Table 1, the standard reduction potential of $\mathrm{Co}^{2+}$ is lower than $\mathrm{Ni}^{2+}$. Therefore, one can expect that nickel ions have more reduction to cobalt ions.

Secondly, the adsorption of smaller cation will be more effective than the larger one, on the same surface. Comparing the radius of nickel and cobalt ions (55 and $69 \mathrm{ppm}$ for $\mathrm{Ni}^{2+}$ at coordination number $(\mathrm{CN})$ of IV and VI, 58 and $74 \mathrm{pm}$ 
TABLE 2: Comparative applicability of ZVI nanoparticles for removal of nickel and cobalt ions.

\begin{tabular}{|c|c|c|c|c|c|}
\hline $\begin{array}{l}\text { Surface area of nanoparticles } \\
\left(\mathrm{m}^{2} / \mathrm{g}\right)\end{array}$ & $\begin{array}{l}\text { Initial concentration of ions } \\
(\mathrm{mg} / \mathrm{L})\end{array}$ & Ion & Removal percentage & $\begin{array}{c}\text { Amount of } \\
\text { nanoparticle }(\mathrm{g} / \mathrm{L})\end{array}$ & Reference \\
\hline $55-75$ & 50 & $\mathrm{Ni}^{2+}$ & 100 & 0.8 & Present work \\
\hline $55-75$ & 50 & $\mathrm{Co}^{2+}$ & 100 & 0.8 & Present work \\
\hline 35 & 100 & $\mathrm{Ni}^{2+}$ & 100 & 5 & {$[28]$} \\
\hline- & 100 & $\mathrm{Ni}^{2+}$ & 71 & 5 & [25] \\
\hline 14.2 & 50 & $\mathrm{Co}^{2+}$ & 96 & 1.25 & [31] \\
\hline
\end{tabular}

TABLE 3: The removal efficiency of nickel and cobalt ions in solutions containing both ions by applying sonication in optimum times.

\begin{tabular}{cccccc}
\hline Entry & $\begin{array}{c}\text { Initial concentration of } \\
\mathrm{Ni}^{2+}(\mathrm{mg} / \mathrm{L})\end{array}$ & $\begin{array}{c}\text { Initial concentration of } \\
\mathrm{Co}^{2+}(\mathrm{mg} / \mathrm{L})\end{array}$ & $\begin{array}{c}\text { Optimum sonication } \\
\text { time }(\mathrm{min})\end{array}$ & $\mathrm{Removed} \mathrm{Ni}^{2+}(\mathrm{mg} / \mathrm{L})$ & $\mathrm{Removed} \mathrm{Co}{ }^{2+}(\mathrm{mg} / \mathrm{L})$ \\
\hline 1 & 50 & 5 & 30 & 25 & 5 \\
2 & 50 & 15 & 30 & 30 & 10 \\
3 & 50 & 25 & 30 & 30 & 14 \\
4 & 50 & 35 & 30 & 31 & 13 \\
5 & 50 & 50 & 30 & 32 & 13 \\
6 & 50 & 75 & 30 & & 3 \\
\hline
\end{tabular}

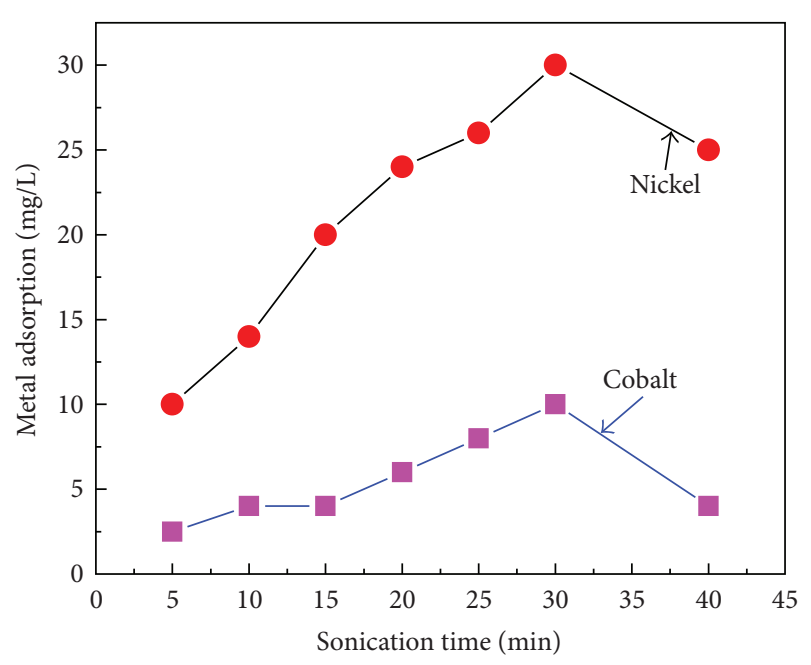

Figure 3: The effect of sonication times on the removal of $\mathrm{Ni}^{2+}$ $(50 \mathrm{mg} / \mathrm{L})$ and $\mathrm{Co}^{2+}(15 \mathrm{mg} / \mathrm{L})$ in solutions containing both ions by ZVI nanoparticles $(0.03$ gr/L).

for $\mathrm{Co}^{2+}$ at $\mathrm{CN}$ of IV and VI, resp.) shows that the radius of these ions has not any role in this enhancement. Finally, due to the more magnetism of $\mathrm{Co}^{2+}$ than $\mathrm{Ni}^{2+}\left(\mu_{\mathrm{Co}^{2+}}=\sqrt{15}\right.$ $\left.\mathrm{BM}, \mu_{\mathrm{Ni}^{2+}}=\sqrt{8} \mathrm{BM}\right)$, the more adsorption of $\mathrm{Co}^{2+}$ on the surface of iron ZVI nanoparticles is expected. Since the ZVI nanoparticles have permanent magnetism, more magnetism of $\mathrm{Co}^{2+}$ plays an important role on the removal efficiency of these ions in their solutions.

Furthermore, there is dissimilarity in optimum sonication times for $\mathrm{Ni}^{2+}$ and $\mathrm{CO}^{2+}$, which are about 20 and 30 minutes, respectively (Figures 1 and 2). The more optimum sonication time for $\mathrm{CO}^{2+}$ can be attributed to the kinetic mechanism of electron transfer from ZVI nanoparticles to $\mathrm{Co}^{2+}$ ions.

In the next step, the amount of ZVI nanoparticles was increased from 0.03 to $0.8 \mathrm{gr} / \mathrm{L}$ while the concentrations of nickel and cobalt solutions were kept constant $(50 \mathrm{mg} / \mathrm{L})$. By increasing the amount of ZVI nanoparticles, the removal efficiency was increased so that 0.8 gr ZVI nanoparticles can remove all of the cobalt and nickel ions from their solutions (Table 2).

We have compared some previously reported data and ours for the removal of nickel and cobalt ions in terms of the surface area, initial concentrations, size, and amounts of ZVI nanoparticles (Table 2). As one can see, our system shows a wide applicability and a very good comparability with previously reported data. The improved performance may be attributed to the smaller size and the higher surface to volume ratio of our ZVI nanoparticles and the use of sonication.

In continue, the effect of $\mathrm{Co}^{2+}$ on the removal of $\mathrm{Ni}^{2+}$ was investigated. Six samples containing constant concentrations of $\mathrm{Ni}^{2+}(50 \mathrm{mg} / \mathrm{L})$ and different concentrations of $\mathrm{Co}^{2+}(15$ to $75 \mathrm{mg} / \mathrm{L}$ ) were prepared and sonicated at different times (5-40 minutes). Figure 3 presents the effect of sonication time on the adsorption of $\mathrm{Ni}^{2+}(50 \mathrm{mg} / \mathrm{L})$ and $\mathrm{Co}^{2+}(15 \mathrm{mg} / \mathrm{L})$ in the same solution in the presence of ZVI nanoparticles $(0.03 \mathrm{gr} / \mathrm{L})$.

The removal efficiency of these ions along with the optimum sonication times are summarized in Table 3. As one can see, the $\mathrm{Ni}^{2+}$ adsorption was increased at initial $\mathrm{Co}^{2+}$ concentrations and then became constant at around $25 \mathrm{mg} / \mathrm{L}$. The maximum removal efficiency of $\mathrm{Ni}^{2+}$ is as high as its amount in Figure 1. Increasing the amount of cobalt ions had less effect on the removal efficiency of nickel 
(Figures 1 and 3), and the optimum sonication time was changed from 20 minutes to 30 minutes. Although the overall removal efficiency (regarding to both $\mathrm{Ni}^{2+}$ and $\mathrm{Co}^{2+}$ ions) is increased, but the level of cobalt adsorption is less than when we have only cobalt ions in the solution (Table 3). It seems that the adsorption mechanism of $\mathrm{Co}^{2+}$ and $\mathrm{Ni}^{2+}$ from $\mathrm{Co}^{2+}$ and $\mathrm{Ni}^{2+}$ solution is different from the adsorption mechanism of $\mathrm{Co}^{2+}$ and $\mathrm{Ni}^{2+}$ from pure $\mathrm{Co}^{2+}$ or $\mathrm{Ni}^{2+}$ solution. In the $\mathrm{Co}^{2+}$ and $\mathrm{Ni}^{2+}$ solution, $\mathrm{Co}^{2+}$ rapidly surround the ZVI nanoparticles and redox reactions occurred. In this state, a lot of $\mathrm{Co}^{0}$ tend again to do redox reactions with $\mathrm{Ni}^{2+}$. Therefore, removal efficiency of $\mathrm{Ni}^{2+}$ is more than removal efficiency of $\mathrm{Co}^{2+}$. In other words, initial layer of cobalt around ZVI nanoparticles increases the removal efficiency of $\mathrm{Ni}^{2+}$ at the specific time. The above results clearly indicated that $\mathrm{Ni}^{2+}$ and $\mathrm{Co}^{2+}$ removal by ZVI nanoparticles was significantly influenced by the ions in the reacting solution.

\section{Conclusions}

In summary, the nickel and cobalt ions were removed effectively by sonicating the aqueous solutions containing one of the entitled ions in the presence of ZVI nanoparticles. The procedure was simple, quick, and economical and removal efficiency was comparable with previously reported methods. Optimum sonication times for removal of nickel and cobalt ions were 20 and 30 minutes, respectively. Compared to $\mathrm{Ni}^{2+}$, $\mathrm{Co}^{2+}$ removal is favored probably due to its more magnetism. In the presence of cobalt ions, the highest removal efficiency of nickel ions by ZVI nanoparticles was observed to about $64 \%$ which is one of the advantages of this methodology. It should be noted that the presence of both metals in the solution affects on the adsorption efficiency, depending on the initial ion concentrations. For example, removal efficiency of cobalt ions in solutions containing both cobalt and nickel ions decreased significantly.

\section{References}

[1] R. M. Allen-King, R. M. Halket, and D. R. Burris, "Reductive transformation and sorption of cis- and trans-1, 2dichloroethene in a metallic iron-water system," Environmental Toxicology and Chemistry, vol. 16, no. 3, pp. 424-429, 1997.

[2] D. W. Blowes, C. J. Ptacek, S. G. Benner, C. W. T. McRae, T. A. Bennett, and R. W. Puls, "Treatment of inorganic contaminants using permeable reactive barriers," Journal of Contaminant Hydrology, vol. 45, no. 1-2, pp. 123-137, 2000.

[3] T. J. Campbell, D. R. Burris, A. L. Roberts, and J. R. Well, "Trichloroethylene and tetrachloroethylene reduction in a metallic iron-water-vapor batch system," Environmental Toxicology and Chemistry, vol. 16, no. 4, pp. 625-630, 1997.

[4] K. J. Cantrell, D. I. Kaplan, and T. W. Wietsma, "Zero-valent iron for the in situ remediation of selected metals in groundwater," Journal of Hazardous Materials, vol. 42, no. 2, pp. 201-212, 1995.

[5] T. L. Johnson, W. Fish, Y. A. Gorby, and P. G. Tratnyek, "Degradation of carbon tetrachloride by iron metal: complexation effects on the oxide surface," Journal of Contaminant Hydrology, vol. 29, no. 4, pp. 379-398, 1998.
[6] W. S. Orth and R. W. Gillham, "Dechlorination of trichloroethene in aqueous solution using $\mathrm{Fe}^{0}$," Environmental Science \& Technology, vol. 30, no. 1, pp. 66-71, 1996.

[7] R. Rangsivek and M. R. Jekel, "Removal of dissolved metals by zero-valent iron (ZVI): kinetics, equilibria, processes and implications for stormwater runoff treatment," Water Research, vol. 39, no. 17, pp. 4153-4163, 2005.

[8] C. M. Su and R. W. Puls, "Kinetics of trichloroethene reduction by zerovalent iron and tin: pretreatment effect, apparent activation energy, and intermediate products," Environmental Science \& Technology, vol. 33, no. 1, pp. 163-168, 1999.

[9] O. Ozay, S. Ekici, Y. Baran, S. Kubilay, N. Aktas, and N. Sahiner, "Utilization of magnetic hydrogels in the separation of toxic metal ions from aqueous environments," Desalination, vol. 260, no. 1-3, pp. 57-64, 2010.

[10] P. G. Tratnyek and R. L. Johnson, "Nanotechnologies for environmental cleanup," Nano Today, vol. 1, no. 2, pp. 44-48, 2006.

[11] W. X. Zhang, "Nanoscale iron particles for environmental remediation: an overview," Journal of Nanoparticle Research, vol. 5, no. 3-4, pp. 323-332, 2003.

[12] S. S. Chen, H. D. Hsu, and C. W. Li, "A new method to produce nanoscale iron for nitrate removal," Journal of Nanoparticle Research, vol. 6, no. 6, pp. 639-647, 2004.

[13] O. Kenji, A. Jasdanian, H. Shimizu, T. Okita, and K. Kakuya, "Emerging nanotechnologies for site remediation and wastewater treatment," in Proceedings of the 4th International Conference on Remediation of Chlorinated and Recalcitrant Compounds, Paper 2E-01, Monterey, Calif, USA, May 2004.

[14] F. He and D. Zhao, "Preparation and characterization of a new class of starch-stabilized bimetallic nanoparticles for degradation of chlorinated hydrocarbons in water," Environmental Science \& Technology, vol. 39, no. 9, pp. 3314-3320, 2005.

[15] B. Schrick, J. L. Blough, A. D. Jones, and T. E. Mallouk, "Hydrodechlorination of trichloroethylene to hydrocarbons using bimetallic nickel-iron nanoparticles," Chemistry of Materials, vol. 14, no. 12, pp. 5140-5147, 2002.

[16] H. L. Lien and W. X. Zhang, "Transformation of chlorinated methanes by nanoscale iron particles," Journal of Environmental Engineering, vol. 125, no. 11, pp. 1042-1047, 1999.

[17] J. T. Nurmi, P. G. Tratnyek, V. Sarathy et al., "Characterization and properties of metallic iron nanoparticles: spectroscopy, electrochemistry, and kinetics," Environmental Science \& Technology, vol. 39, no. 5, pp. 1221-1230, 2005.

[18] W. X. Zhang, C. B. Wang, and H. L. Lien, "Treatment of chlorinated organic contaminants with nanoscale bimetallic particles," Catalysis Today, vol. 40, no. 4, pp. 387-395, 1998.

[19] C. B. Wang and W. X. Zhang, "Synthesizing nanoscale iron particles for rapid and complete dechlorination of TCE and PCBs," Environmental Science \& Technology, vol. 31, no. 7, pp. 2154-2156, 1997.

[20] Y. Q. Liu, S. A. Majetich, R. D. Tilton, D. S. Sholl, and G. V. Lowry, "TCE dechlorination rates, pathways, and efficiency of nanoscale iron particles with different properties," Environmental Science \& Technology, vol. 39, no. 5, pp. 1338-1345, 2005.

[21] J. Cao and W. X. Zhang, "Stabilization of chromium ore processing residue (COPR) with nanoscale iron particles," Journal of Hazardous Materials, vol. 132, no. 2-3, pp. 213-219, 2006.

[22] S. M. Ponder, J. G. Darab, J. Bucher et al., "Surface chemistry and electrochemistry of supported zerovalent iron nanoparticles in the remediation of aqueous metal contaminants," Chemistry of Materials, vol. 13, no. 2, pp. 479-486, 2001. 
[23] Y. Xu and D. Zhao, "Reductive immobilization of chromate in water and soil using stabilized iron nanoparticles," Water Research, vol. 41, no. 10, pp. 2101-2108, 2007.

[24] S. M. Ponder, J. G. Darab, and T. E. Mallouk, "Remediation of $\mathrm{Cr}(\mathrm{VI})$ and $\mathrm{Pb}(\mathrm{II})$ aqueous solutions using supported, nanoscale zero-valent iron," Environmental Science \& Technology, vol. 34, no. 12, pp. 2564-2569, 2000.

[25] X. Q. Li and W. X. Zhang, "Sequestration of metal cations with zerovalent iron nanoparticles-a study with high resolution X-ray photoelectron spectroscopy (HR-XPS)," The Journal of Physical Chemistry C, vol. 111, no. 19, pp. 6939-6946, 2007.

[26] S. Bang, M. D. Johnson, G. P. Korfiatis, and X. Meng, "Chemical reactions between arsenic and zero-valent iron in water," Water Research, vol. 39, no. 5, pp. 763-770, 2005.

[27] X. Q. Li, J. Cao, and W. X. Zhang, "Stoichiometry of Cr(VI) immobilization using nanoscale zero valent iron (NZVI): a study with high-resolution X-ray photoelectron spectroscopy (HR-XPS)," Industrial and Engineering Chemistry Research, vol. 47, no. 7, pp. 2131-2139, 2008.

[28] X. Q. Li and W. X. Zhang, "Iron nanoparticles: the coreshell structure and unique properties for $\mathrm{Ni}(\mathrm{II})$ sequestration," Langmuir, vol. 22, no. 10, pp. 4638-4642, 2006.

[29] Ç. Üzüm, T. Shahwan, A. E. Ero囚lu, I. Lieberwirth, T. B. Scott, and K. R. Hallam, "Application of zero-valent iron nanoparticles for the removal of aqueous $\mathrm{Co}^{2+}$ ions under various experimental conditions," Chemical Engineering Journal, vol. 144, no. 2, pp. 213-220, 2008.

[30] P. Atkins and J. D. Paula, Physical Chemistry, Oxford University Press, New York, NY, USA, 8th edition, 2006.

[31] K. Kwak and C. Kim, "Viscosity and thermal conductivity of copper oxide nanofluid dispersed in ethylene glycol," KoreaAustralia Rheology Journal, vol. 17, no. 2, pp. 35-40, 2005. 

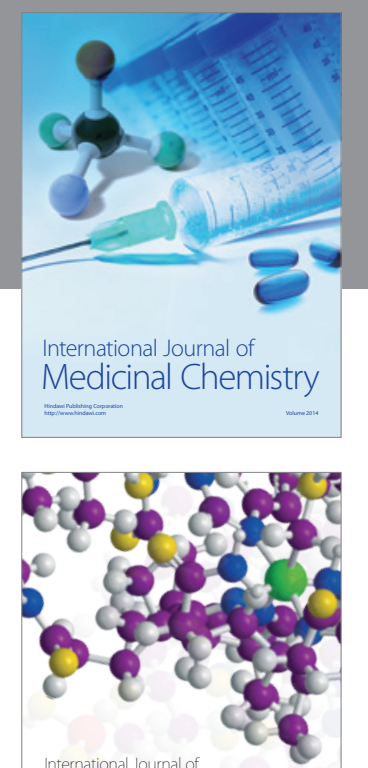

\section{Carbohydrate} Chemistry

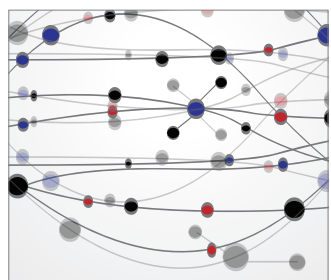

The Scientific World Journal
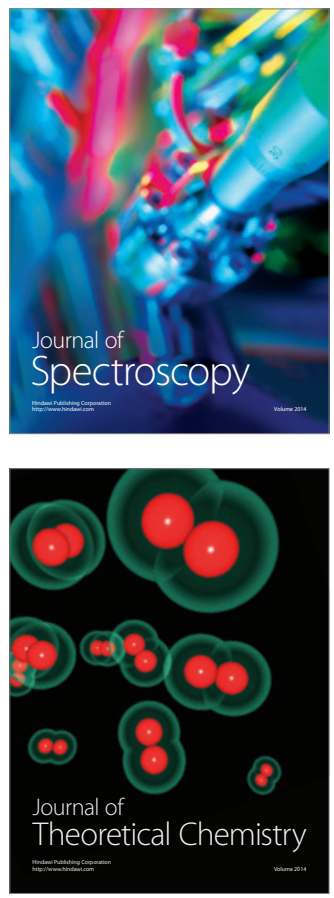
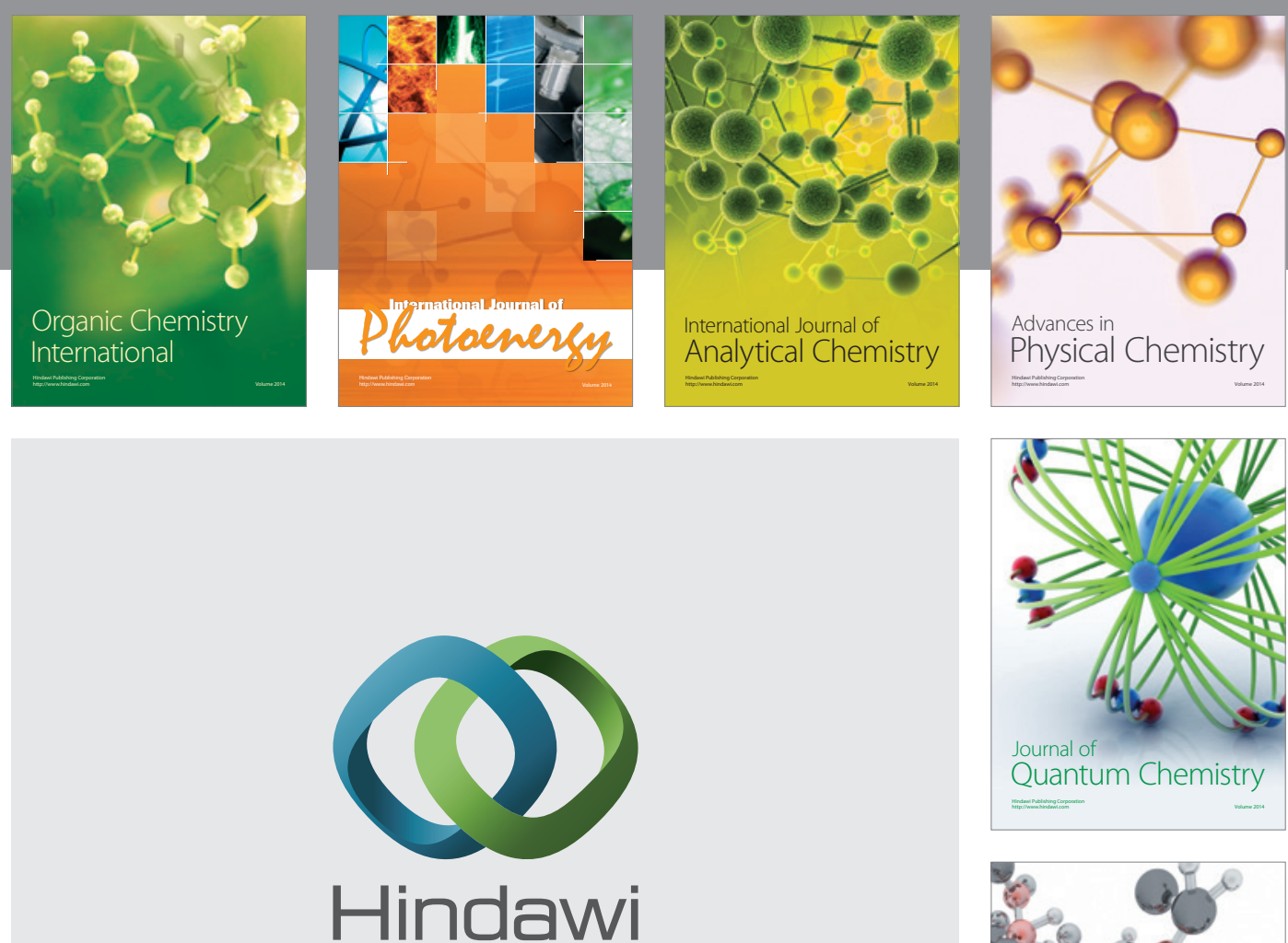

Submit your manuscripts at

http://www.hindawi.com

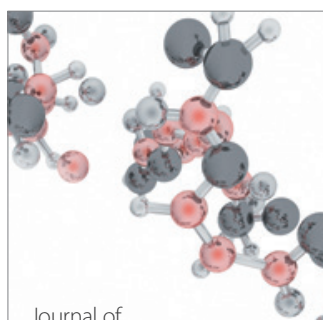

Analytical Methods

in Chemistry

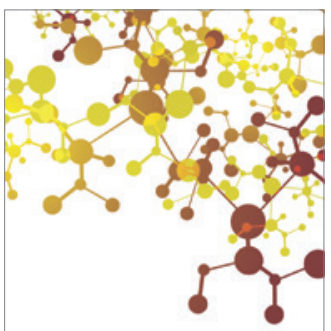

Journal of

Applied Chemistry

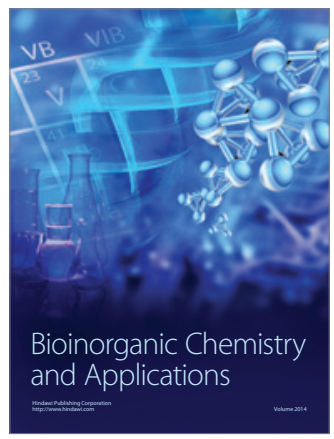

Inorganic Chemistry
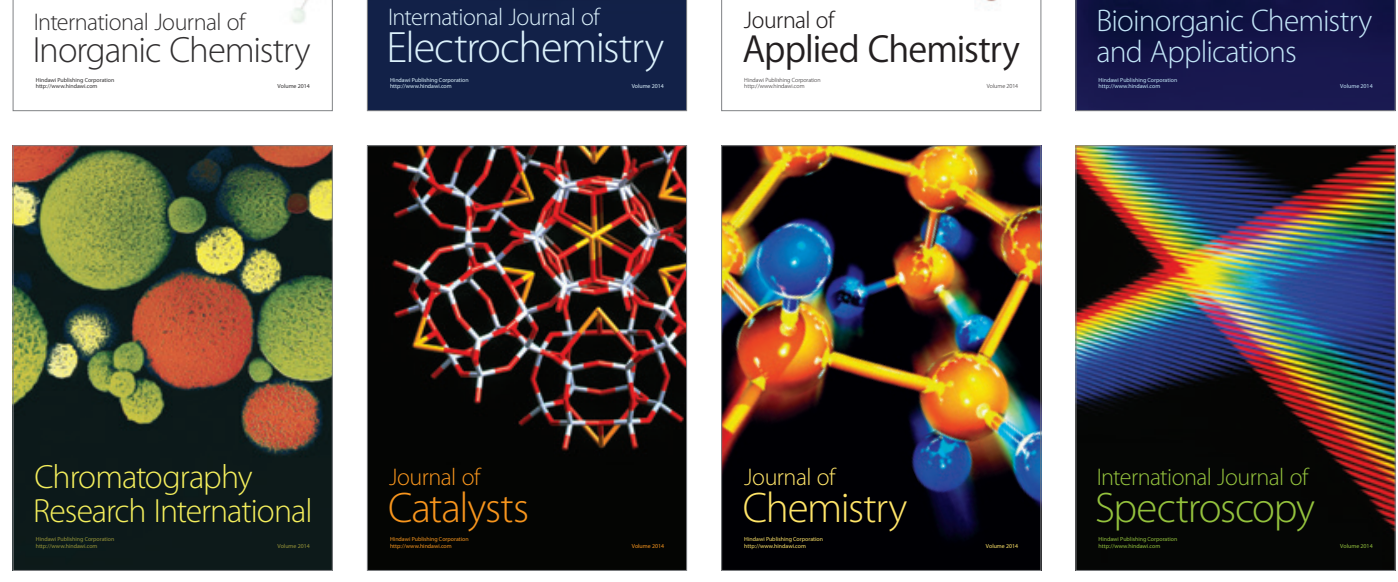